\title{
Fine mapping and identification of candidate genes for a QTL affecting Meloidogyne incognita reproduction in Upland cotton
}

Pawan Kumar ${ }^{1 \dagger}$, Yajun He ${ }^{1,7 \dagger}$, Rippy Singh ${ }^{1}$, Richard F. Davis², Hui Guo ${ }^{3}$, Andrew H. Paterson ${ }^{3}$, Daniel G. Peterson ${ }^{4}$, Xinlian Shen ${ }^{1,6}$, Robert L. Nichols ${ }^{5}$ and Peng W. Chee ${ }^{1 *}$

\begin{abstract}
Background: The southern root-knot nematode (Meloidogyne incognita; RKN) is one of the most important economic pests of Upland cotton (Gossypium hirsutum L.). Host plant resistance, the ability of a plant to suppress nematode reproduction, is the most economical, practical, and environmentally sound method to provide protection against this subterranean pest. The resistant line Auburn 623RNR and a number of elite breeding lines derived from it remain the most important source of root-knot nematode (RKN) resistance. Prior genetic analysis has identified two epistatically interacting RKN resistance QTLs, qMi-C11 and qMi-C14, affecting gall formation and RKN reproduction, respectively.

Results: We developed a genetic population segregating only for the qMi-C14 locus and evaluated the genetic effects of this QTL on RKN resistance in the absence of the qMi-C11 locus. The qMi-C14 locus had a LOD score of 12 and accounted for $24.5 \%$ of total phenotypic variation for egg production. In addition to not being significantly associated with gall formation, this locus had a lower main effect on RKN reproduction than found in our previous study, which lends further support to evidence of epistasis with qMi-C11 in imparting RKN resistance in the Auburn 623RNR source. The locus qMi-C14 was fine-mapped with the addition of 16 newly developed markers. By using the reference genome sequence of G. raimondii, we identified 20 candidate genes encoding disease resistance protein homologs in the newly defined $2.3 \mathrm{Mb}$ region flanked by two SSR markers. Resequencing of an RKN resistant and susceptible G. hirsutum germplasm revealed non-synonymous mutations in only four of the coding regions of candidate genes, and these four genes are consequently of high interest.

Conclusions: Our mapping results validated the effects of the qMi-C14 resistance locus, delimiting the QTL to a smaller region, and identified tightly linked SSR markers to improve the efficiency of marker-assisted selection. The candidate genes identified warrant functional studies that will help in identifying and characterizing the actual qMi-C14 defense gene(s) against root-knot nematodes.
\end{abstract}

Keywords: Cotton, Root Knot Nematodes, RKN, QTLs, SNP, Candidate genes

\footnotetext{
* Correspondence: pwchee@uga.edu

${ }^{\dagger}$ Equal contributors

${ }^{1}$ Cotton Molecular Breeding Laboratory, University of Georgia, Tifton, GA

31793, USA

Full list of author information is available at the end of the article
} 


\section{Background}

Plant-parasitic nematodes are important pests in agriculture and are found across a broad range of climatic conditions. The genus Meloidogyne includes more than 70 species; four species - M. incognita, M. arenaria, $M$. javanica and $M$. hapla - account for approximately $95 \%$ of the total crop area infested by this genus [1]. The Southern root-knot nematode (Meloidogyne incognita, RKN) is the most important parasitic nematode of Upland cotton inflicting economic losses through direct damage to the plant root system and indirectly through increasing severity of other root diseases such as Fusarium Wilt caused by Fusarium oxysporum f. sp. vasinfectum. Yield loss due to RKN has dramatically increased in the U.S. from $1 \%$ in 1987 to $5.5 \%$ in 2006, resulting in losses of more than 300 million pounds (4.4\%) of cotton valued over $\$ 235$ million (Cotton Disease Loss Estimate Committee Report 2012). Recommended management practices to control RKN include crop rotation and nematicide application. The broad host-range of RKN leaves cotton growers with few profitable options to adopt crop rotation as a means of nematode management [2]. Nematicides applied at planting fail to provide season long protection; moreover, the future availability of most widely used cotton nematicide, aldicarb, is uncertain.

Host plant resistance can be an efficient RKN management tool in cotton production. Resistant varieties can offer good to excellent pest control efficacy and are also environmentally sound alternatives. Both cultivated and wild relatives of Upland cotton have been screened to identify germplasm displaying high levels of RKN resistance [3], and a few resistance sources were identified. Currently, the Auburn 623 RNR germplasm line is the most important source of RKN resistance because it displays near immunity to RKN infection. The resistance in Auburn 623 RNR is believed to have originated from transgressive segregation in a cross between two moderately resistant parents, Clevewilt 6 and Wild Mexican Jack Jones [4, 5]. Resistance in Auburn 623 RNR was transferred to several adapted cultivars through backcrossing, resulting in the release of M-lines with improved agronomic qualities while retaining nearimmunity to RKN [4].

Quantitative trait locus (QTL) mapping studies have identified regions on the long arm of Chromosome 11 and the short arm of Chromosome 14 that confer RKN resistance in Auburn 623 RNR derived M-lines [6-8]. Origin of the resistance loci was traced to the two moderately resistant parents of Auburn 623 RNR, with the $q M i-C 11$ locus on Chromosome 11 inherited from Clevewilt 6 [8] and the $q M i-C 14$ locus on Chromosome 14 inherited from Wild Mexican Jack Jones [7, 8]. The $q \mathrm{Mi}-\mathrm{C} 11$ locus was recently fine mapped to a $3.6 \mathrm{cM}$ interval [6], however the QTL region near $q M i-C 14$ remains sparsely mapped $[8,9]$.

Recent studies suggested that the $q M i-C 11$ locus predominanly affects root gall suppression whereas the $q \mathrm{Mi}-\mathrm{C} 14$ locus largely reduces egg production but has little effect on galling [9]. Further, while the main effects of each QTL appeared to serve as the major genetic basis in conferring resistance for both galling and egg production phenotypes, additive $\mathrm{x}$ additive epistatic interaction was important in suppressing nematode egg production, resulting in a near-immunity to infection when both QTLs are present [9]. These studies support earlier histo-pathological observations indicating that a two-stage defense mechanism was responsible for resistance in Auburn 623 RNR. The first stage involved suppressing the development of giant cells at 6 days post penetration and the second stage involved reducing the egg production of $M$. incognita females at 24 days post penetration $[10,11]$.

The presence of two or more unlinked resistance loci with different mechanisms in the Auburn 623 RNR source has complicated elucidating the mode of inheritance and determining the genetic effects of each resistance gene. For example, Zhou et al. [12] reported that RKN resistance in the Auburn 623 RNR source involved a partially dominant and a recessive gene. However, McPherson et al. [13] suggested that resistance in the Auburn 623 RNR source was due to a dominant and an additive gene, and Zhang et al. [14] concluded that resistance was controlled by at least two additive genes. To better determine the genetic effects of each resistance locus and to investigate the hypothesis of independent resistance genes controlling plant responses to suppression of root galling and nematode reproduction in this resistance source would require testing a genetic population segregating for only a single resistance locus.

Host-plant resistance to root-knot nematodes was first identified in Lycopersicum peruvianum Mill., a wild relative of cultivated tomato [15] where a single dominant $\mathrm{Mi}$ gene conferred resistance to three major root-knot nematodes $M$. arenaria, $M$. incognita and $M$. hapla. Further molecular characterization of the $M i$ gene revealed that it encodes a protein with nucleotide-binding site leucine-rich repeat (NBS-LRR) motifs [16] and triggers a hypersensitive response in the host plant. Based on the amino acid motifs and their membrane spanning domains [17], disease resistance genes in plants are grouped into eight classes and a majority of these genes are characterized by the presence of Leucine Rich Repeat (LRRs) motifs. The several classes of LRR-containing proteins that exist in plants have diverse overall structures and functions. They provide an early warning system for the presence of potential pathogens and activate protective immune signaling in plants $[18,19]$. In 
addition, they act as a signal amplifier in the case of tissue damage, establishing symbiotic relationships and affecting developmental processes [20].

In this study, we developed a genetic population segregating only for the $q \mathrm{Mi}-\mathrm{C} 14$ resistance locus. Our objectives were to: (1) develop and map new SSR markers to construct a dense linkage map near the $q M i-C 14$ locus, (2) estimate the genetic effect of $q M i-C 14$ on RKN resistance and (3) predict putative candidate genes responsible for the $q \mathrm{Mi}-\mathrm{C} 14$ resistance by identifying genes that encode for LRR-containing proteins within the QTL interval.

\section{Methods}

\section{Population development}

The mapping population was derived from an interspecific cross between the highly resistant Upland cotton line M-120 RNR, and an RKN susceptible G. barbadense cultivar Pima S-6 as described by Shen et al. [7]. A total of $1252 \mathrm{~F}_{2}$ individuals were planted in a greenhouse and screened with previously published SSRs mapped to chromosomes 11 and $14[6,7,9]$. Seven $F_{2}$ individuals that were completely heterozygous at the $q \mathrm{Mi}$-C14 locus on Chromosome 14 as determined by five previously mapped co-dominant SSR markers (CIR246, JESPR156, UGT045, CGR5668, and STV30) [9] but were homozygous for the Pima S-6 allele at the $q M i-C 11$ locus as determined by CIR069 and CIR316 on chromosome 11 (for absence of resistance allele) were identified. All seven plants were self-pollinated to yield a genetic population consisting of 513 plants segregating only for the qMi-C14 locus.

\section{Phenotypic screening and data analysis}

The mapping population was planted in a greenhouse along with ten plants each of the parental lines, M-120 RNR and Pima S-6, as resistant and susceptible checks, respectively. The screening method to determine the level of resistance to RKN has been described previously by Shen et al [7]. One hour prior to inoculation, nematode eggs were collected by agitating infected eggplant roots (Solanum melongena L.) in $0.5 \%$ sodium hypochlorite solution for two minutes [21]. Three week old plants were inoculated with approximately 8000 eggs of $M$. incognita race 3 (approximately 450 eggs $150 \mathrm{~cm}^{-3}$ soil). Inoculum was distributed into two holes about $2.5 \mathrm{~cm}$ deep in soil on opposite sides of the seedling and the holes were covered with soil after inoculation. The soil temperatures varied between $17^{\circ} \mathrm{C}$ and $28^{\circ} \mathrm{C}$. Plants were evaluated for the amount of $M$. incognita reproduction at 56 to 58 days after inoculation. Phenotypic data collected included root galling index (RGI), total number of eggs extracted, and the number of eggs per gram of fresh root. Roots were washed free of soil, evaluated for galling, weighed, cut into $5-\mathrm{cm}$ pieces, and agitated in a $1 \% \mathrm{v} / \mathrm{v}$ sodium hypochlorite solution in a 1-liter flask for four minutes [21]. Eggs were collected and rinsed with tap water on nested 150 - over $25-\mu$ mpore sieves. Root galling index (RGI) was evaluated using the 0 to 10 scale where $0=$ no galling, $1=1-10 \%$ of the root system galled, $2=11-20 \%$ of the root system galled, up to $10=91-100 \%$ of the root system galled [22]. Roots of each plant were harvested and weighed immediately prior to extraction of eggs. Eggs were extracted from the whole root system and counted. The mean number of eggs per gram of fresh root (eggs/g of root) was evaluated in order to standardize egg counts.

Statistical parameters describing the population for each phenotypic trait were calculated using SAS (SAS, ver. 9.3). Fisher's Least Significant Difference (LSD) test was used to compare phenotypic means for all traits between mapping parents. Data for total egg count and eggs per gram of root weight were $\log _{10}(x+1)$ transformed to achieve a normalized distribution for QTL analysis.

\section{SSR mining and primer design}

He et al. [9] and Gutierrez et al. [8] indicated that the RKN resistance locus on chromosome 14 is flanked by BNL3545 and CGR5668; therefore, we used the sequences from which these two SSRs (available at www.cottongen.org) to BLAST search the genome sequence of G. raimondii at www.phytozome.net (version 9.1). The physical location of the $q M i-C 14$ locus was found to be on the distal end of G. raimondii chromosome 05 . More than $4 \mathrm{Mbp}$ of sequence from the distal end of this chromosome was downloaded in fasta file format, divided into two equal segments of $2 \mathrm{Mbp}$ each, and scanned for short repeating units using a web based microsatellite repeat finder (insilico.ehu.es/mini_tools/ microsatellites). Search parameters were: minimum number of repeats $=5$, minimum repeat unit length $=2$, maximum repeat unit length $=10$. Fifty microsatellites that were between 10-25 repeats long were selected; these microsatellites are fairly uniformly distributed along the 4 Mbp region. Three hundred base pairs on each side of each microsatellite were selected for primer development using the web based BatchPrimer3 software [23]. Primers were 20-22 nt long and designed to amplify 150-200 bp PCR products at melting temperatures between $50-55^{\circ} \mathrm{C}$. Primers were commercially synthesized by Eurofins MWG Operon (Huntsville, AL).

PCR reaction conditions were slightly modified from a previously described protocol [24]. PCR amplification was performed in a PTC-100 or PTC-200 thermocycler (MJ Research Inc.). A $10 \mu \mathrm{l}$ reaction contained $10 \mathrm{ng}$ of template DNA, $0.5 \mu \mathrm{M}$ primer mix, $100 \mu \mathrm{M}$ dNTPs, $1.5 \mathrm{mM} \mathrm{MgCl}_{2}, 3 \mathrm{U}$ of DNA polymerase, and $1 \mathrm{X}$ reaction 
buffer (100 mM Tris- $\mathrm{mCl}, \mathrm{pH} 8.3,500 \mathrm{mM} \mathrm{KCl})$. The cycling conditions for PCR were $94{ }^{\circ} \mathrm{C}$ for $3 \mathrm{~min}$, followed by 35 cycles of $94{ }^{\circ} \mathrm{C}$ for $1 \mathrm{~min}, 55{ }^{\circ} \mathrm{C}$ for $1 \mathrm{~min}$, and $72{ }^{\circ} \mathrm{C}$ for $1.2 \mathrm{~min}$. After the last cycle, reactions were incubated at $72{ }^{\circ} \mathrm{C}$ for $6 \mathrm{~min}$ before cooling to $4{ }^{\circ} \mathrm{C}$. The amplified PCR products were separated by electrophoresis on a $10 \% \mathrm{w} / \mathrm{v}$ non-denaturing polyacrylamide gel (PAGE) and visualized by staining with silver nitrate following published procedures [25].

\section{Linkage map construction and QTL mapping}

Procedures for linkage map development and QTL analysis were as described by $\mathrm{He}$ et al. [9]. Briefly, all markers were first tested for their ability to detect polymorphism between the M-120 RNR and Pima S-6 parents. Primers that detected clear polymorphism between parents were utilized to genotype the entire mapping population. Linkage groups were constructed using the Mapmaker/EXP 3.0 [26] software. Linkage group assembly was done using the 'group' command with a LOD score of 3.0 and a maximum recombination fraction of $30 \mathrm{cM}$. Recombination units were converted into genetic distances by using the Kosambi mapping function [27] with the "error detection" command on. New markers were added to the framework using the 'try' and 'compare' commands. The final order of markers on a linkage group was confirmed using the 'ripple' command.

Detection of QTLs and estimation of various genetic parameters were performed by Composite Interval Mapping (CIM) function implemented in the software WinQTL Cartographer version 2.5 [28]. Likelihood ratio (LR) threshold values $(\alpha=0.05)$ for declaring the presence of QTLs were estimated after 1000 permutations [29]. Mapping was performed at $1 \mathrm{cM}$ walk speed in a $10 \mathrm{cM}$ window using five background cofactors selected via forward-backward stepwise regression. QTLs were defined by one-LOD likelihood intervals on either side of the peak position.

\section{Identification of potential candidate genes}

The reference genome sequence of the $\mathrm{D}$ genome diploid $G$. raimondii and the assembled $D_{t}$ subgenome of the tetraploid G. hirsutum were downloaded from CottonGen (http://www.cottongen.org) along with their GFF3 gene annotation files. The physical region between markers BNL3545 and STV030 was identified in both genome sequences and scanned for annotated genes using the Multiple Sequence Comparison by LogExpectation software [30]. Genes with Leucine Rich Repeat (LRR) N-terminal domains were shortlisted as potential candidate genes that may be involved in a nematode resistance. Protein sequences encoded by these genes were further used for blastp (protein-protein blast) search to identify protein homologs in the protein database of GenBank. A neighbor joining method was utilized to construct the phylogenetic tree using the MEGA 6.0 software [31].

\section{Identification of single nucleotide variations}

Genomes of an RKN susceptible cotton line, Acala 'Maxxa' (SRA061309), and an RKN resistant line, GA120R1B3 (SRA068148), were sequenced at 82x and $30 \mathrm{x}$ read depth respectively by Illumina sequencing of paired-end libraries [32]. Using the cotton D-genome sequence as reference [33], short reads were aligned using the Burrows-Wheeler Aligner (BWA) [34]. Single nucleotide polymorphism (SNPs) between candidate gene alleles in RKN resistant and susceptible lines were called with Samtools/bcftools [35, 36] using reads with mapping quality $>30$ and base quality $>30$ [32].

\section{Results}

\section{Population biometrical parameters}

The distribution of resistance reaction phenotypes for the parents and the mapping population is presented in Fig. 1. The resistant parent, M-120 RNR had significantly $(P<0.001)$ lower galling, total eggs, and eggs $\mathrm{g}^{-1}$ root than the susceptible parent, Pima S-6. A nonnormal distribution was observed for total eggs and eggs $\mathrm{g}^{-1}$ root (skewness $>1.0$ ) with greater number of individuals skewed towards the M-120 RNR parent, suggesting a dominant nature of the gene(s) underlying RKN resistance on chromosome 14. A strong correlation was observed between eggs pot $^{-1}$ and eggs $\mathrm{g}^{-1}$ root $(r=0.83$, $p<0.0001)$. However, RGI had a weak correlation with eggs $\operatorname{pot}^{-1}(r=0.19, p<0.01)$ and eggs $g^{-1}$ root $(r=0.18$, $p<0.05$ ), suggesting that RGI and egg production were genetically independent but together contribute toward RKN resistance in the mapping population. Root weight was not correlated with RGI or eggs $\mathrm{g}^{-1}$ root but was moderately correlated with eggs $\operatorname{pot}^{-1}(r=$ $0.36, p<0.0001)$.

\section{New SSR marker development and mapping}

A total of 801 microsatellites were found on the $4 \mathrm{Mb}$ region of $G$ raimondii chromosome 05 between the two SSR markers BNL3545 and CGR5668, thought to contain $q M i-C 14,405$ microsatellites were identified in the first $2 \mathrm{Mb}$ and 396 in the next $2 \mathrm{Mb}$ region. The distribution of di, tri, tetra, penta and hexa repeats on the two regions is presented in Additional file 1: Figure S1. Of the 801 microsatellites identified, 624 (77.9\%) dinucleotide repeats and 135 were tri-nucleotide repeats with unit copy numbers from 5-28. Forty-five SSRs occurring at approximately uniform intervals were selected to fine-map the region between BNL3545 and CGR5668. A polymorphism survey found 27 (60 \%) SSRs 

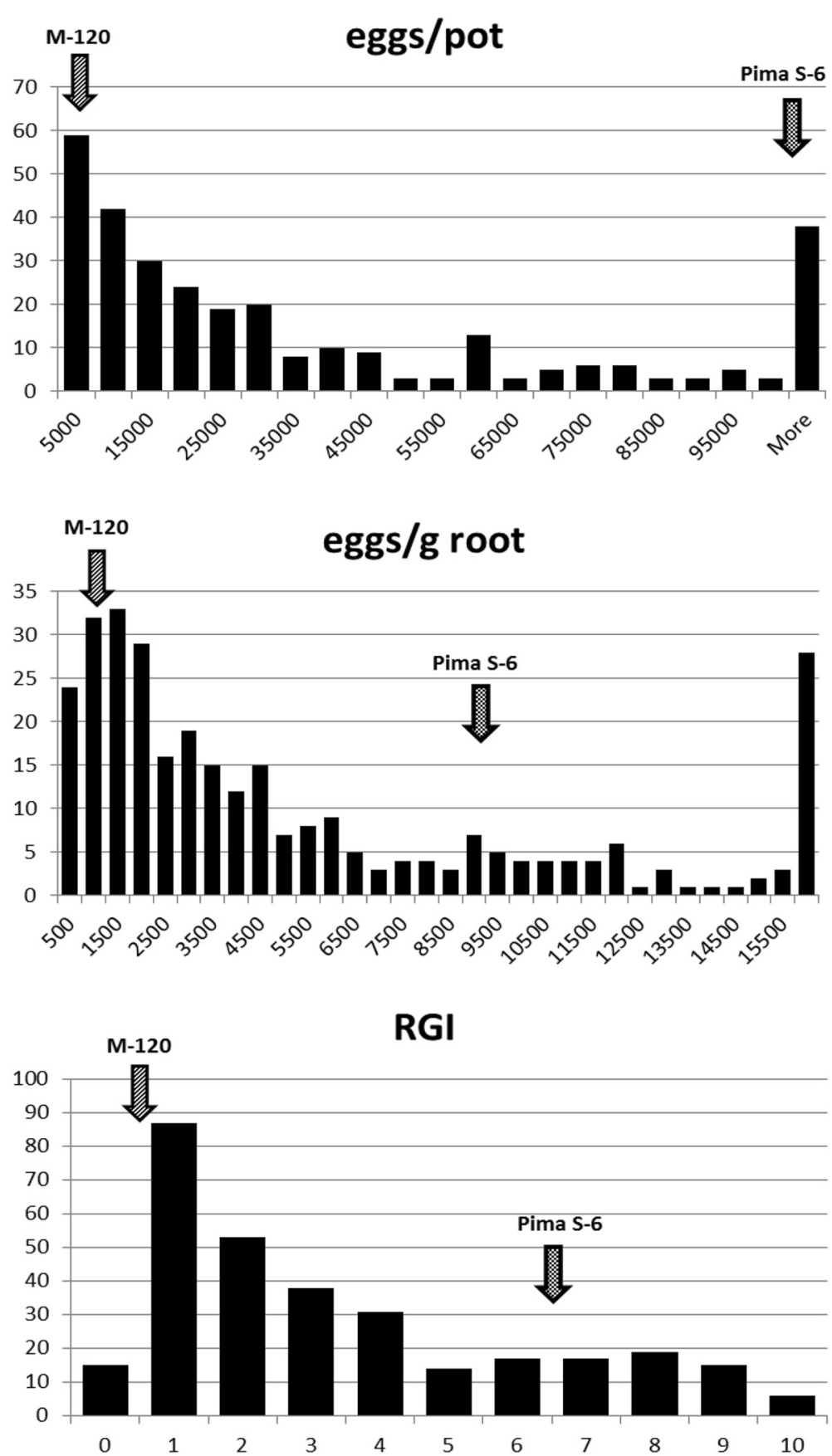

Fig. 1 Phenotypic distribution of Root Galling Index (RGI) and egg production in an $F_{2}$ population segregating for the $M$. incognita resistance QTL 9Mi-C14

to be polymorphic between M-120 RNR and Pima S-6, with $12(27 \%)$ being monomorphic and 6 (13\%) failing to amplify.

Figure 2 shows the localized linkage map of the qMi-C14 region on chromosome 14. A total of 25 loci were mapped to this region spanning $21.3 \mathrm{cM}$ (average distance of $0.85 \mathrm{cM}$ between markers), 16 of which were newly developed SSR markers and 9 were previously reported by $\mathrm{He}$ et al. [9]. Eleven of the 27 polymorphic markers did not produce scorable fragments or did not map on chromosome 14, and hence were not pursued further in this study. Forward and reverse primer sequences of the 16 new SSR markers are presented in Additional file 2: Table S1. No significant segregation distortion was observed for any of these markers. 


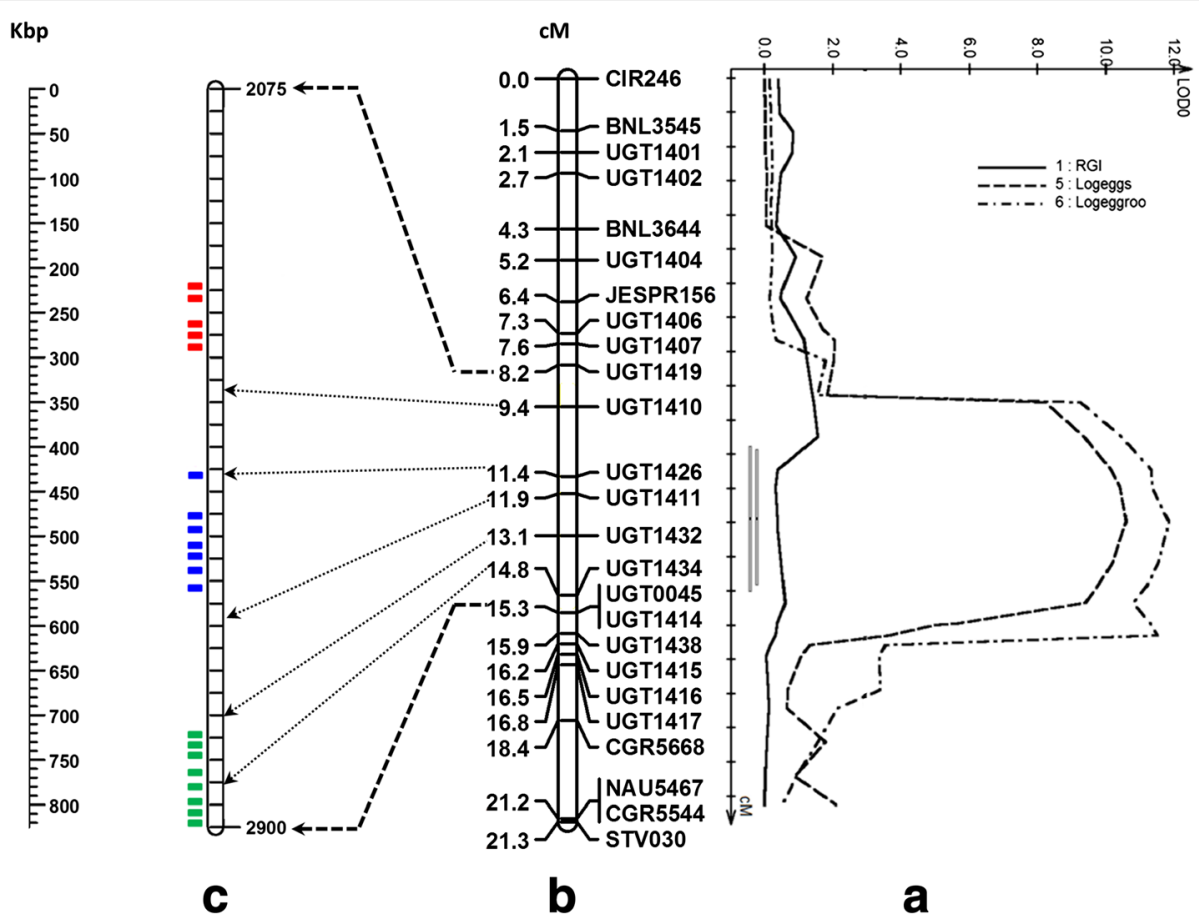

Fig. 2 Genetic and physical position of qMi-C14 on chromosome 14. a LOD profile of the QTL region affecting RKN egg production; b Linkage map of the telomeric region; and $\mathbf{c}$ Physical location of the three clusters of candidate genes, identified with different colors

\section{Association analyses}

Because these phenotypes displayed a non-normal distribution, log transformed data for total eggs and eggs $\mathrm{g}^{-1}$ of root phenotypes were used for further analysis. Composite interval mapping detected a major QTL for total eggs and eggs $\mathrm{g}^{-1}$ root near the marker UGT1432, with the allele from the resistant parent M-120 RNR increasing nematode resistance for all phenotypes. The QTL peak for both phenotypes was located at the $12.9 \mathrm{cM}$ position with a LOD value of 10.7 and 11.8 , respectively. These QTLs explained up to $21.5 \%$ and $24.6 \%$ of phenotypic variation for total eggs and eggs $\mathrm{g}^{-1}$ root, respectively. The likelihood interval, circumscribed by a one LOD score drop on either side of the peak, covered $3.9 \mathrm{cM}$ and was flanked by markers UGT1426 and UGT1414 (Fig. 2). The d/a ratio was 0.1 for both phenotypes, indicating that the gene action for this QTL is additive. Interestingly, there was no significant association with RGI suggesting that this region has no effect on suppressing root galling.

To more precisely evaluate the genetic effect of $q M i$ C14, all individuals homozygous for the M-120 RNR alleles, homozygous for the Pima S- 6 alleles and heterozygous for the entire region between BNL3545 and STV030 that flanks the $q M i-C 14$ locus, were selected for further analysis (Fig. 3). In total, 50 individuals were completely homozygous for the M-120 RNR allele, 55 were completely homozygous for Pima S-6 alleles and
119 were completely heterozygous for the region between BNL3545 and STV030. Differences in phenotypic means for total eggs and eggs $\mathrm{g}^{-1}$ root between the two homozygous classes were highly significant $(P<0.001)$. The difference in phenotypic means for total eggs and eggs $\mathrm{g}^{-1}$ root between the heterozygous class and the Pima homozygous S-6 class was significant, but no significant difference was observed between the heterozygous and the M120 RNR homozygous class (Fig. 3). These results suggest that although the $d / a$ ratio indicates that the gene action was additive, this locus may have dominance effects. No significant difference was observed between the means of the three genotypic classes for RGI or root weight.

\section{Potential candidate genes}

More than 133 annotated genes were identified in the physical region between the markers BNL3545 and STV030 (www.phytozome.net), including 20 in the G. raimondii genome and 13 in the orthologous region from the $D_{t}$ subgenome of $G$. hirsutum (Table 1) that contain leucine rich repeat (LRR) N-terminal domains. Based on the G. raimondii physical map, the LRR candidate genes were distributed into three groups (Fig. 2). Most of the LRR genes within each group shared a high level of homology as indicated by their clustering in the phylogenetic tree drawn from multiple alignments of the protein coding regions of these genes (Fig. 4). For 



Fig. 3 Mean difference between the three genotypic classes in the BNL3545 - STV030 interval. Means were compared $(P<0.001)$ between individuals completely homozygous for the M-120 allele (Homo M120), completely homozygous for Pima S-6 alleles (Homo Pima S6) and completely heterozygous (Hetero)

example, all eight genes in Group III fall into a single clade in the phylogenetic tree. The genes in Group I and II were more similar to each other with two genes in Group I clustering with four genes in Group II, and two genes each in Group I and II forming the third clade in the phylogenetic tree. Finally, the gene Gorai.005G026700 from Group I appears to be the most diverse as it does not cluster with the other groups. The 13 LRR genes identified in the D02 chromosome of G. hirsutum also showed a similar distribution on the physical map and clustering pattern in the phylogenetic tree (Fig. 4). A blast search indicated that all genes except Gorai.005G031600 in G. raimondii showed a high degree of similarity $(E$-value $=0)$ with at least one of the genes found in G. hirsutum. Interestingly, Gorai.005G031600 did not yield any hit on the D02 chromosome of the G. hirsutum $\mathrm{D}_{\mathrm{t}}$ sub-genome, suggesting that it may have been lost from the tetraploid genome.

\section{SNP between RKN resistant and susceptible alleles}

Sequences of protein coding regions (CDS) and untranslated regions ( $5^{\prime}$ and 3'UTRs) of 59 genes between Gorai.005G026300 and Gorai.005G032200 (about 600 $\mathrm{Kbp}$ ), including 20 that contain LRR motifs, were compared between Acala 'Maxxa' (RKN susceptible) and GA120R1B3 (RKN resistant) lines. Twenty-five SNPs were identified in 11 genes that differentiate the RKN resistant line from the susceptible Acala Maxxa (Table 2). SNP alleles in coding regions of four LRR genes in the RKN resistant line GA120R1B3 - Gorai.005G026500, Gorai.005G028600, Gorai.005G029200 and Gorai.005G
029400 - resulted in changes in amino acids relative to Acala Maxxa (Table 2).

\section{Discussion}

Transgressive segregation for RKN resistance from the Auburn 623RNR cotton germplasm is due to the effects of pyramiding of at least two QTLs inherited from different parents; each individually confers moderate resistance, although the two QTLs interact epistatically to confer near-immunity. The $q M i-C 11$ and $q M i-C 14$ loci map to chromosome 11 and 14, respectively [8, 9]. Study of these loci shows that two phenotypes commonly used to measure resistance reaction to RKN, specifically galling index and egg production, could be partly genetically independent, and the qMi-C11 and qMi-C14 loci may provide resistance via different mechanisms $[8,9]$. Full characterization of $\mathrm{qMi}-\mathrm{C} 11$ and $\mathrm{qMi}-\mathrm{C} 14$ will advance our understanding of defense mechanisms against parasitism from RKN, elucidate host-pathogen interactions at the molecular level, and facilitate their use in cotton improvement.

The genetic population used in the current study, consisting of $513 \mathrm{~F}_{2: 3}$ plants, was developed using $\mathrm{F}_{2}$ plants that were heterozygous (and therefore segregating) at the $q \mathrm{Mi}$-C14 locus but homozygous for the susceptible parent allele at the $q M i-C 11$ locus. Without the confounding effects from the $q M i-C 11$ QTL, our data confirmed prior QTL analyses suggesting that the qMi-C14 locus had a highly significant effect on egg production but little or no effect on root galling (Fig. 3). The estimated main genetic effects for this locus was 21.5 to 
Table 1 Physical locations of genes with Leucine Rich Repeat (LRR) domain between SSR markers BNL3545 and STV030 on chromosome 5 of G. raimondii and chromosome D02 of G. hirsutum

\begin{tabular}{|c|c|c|}
\hline Gene name & Physical location & Group \\
\hline Gorai.005G026300 & $2297846-2301061$ & 1 \\
\hline Gorai.005G026400 & $2313103-2316975$ & I \\
\hline Gorai.005G026500 & $2345315-2348063$ & 1 \\
\hline Gorai.005G026600 & $2349170-2352262$ & 1 \\
\hline Gorai.005G026700 & $2361518-2365096$ & । \\
\hline Gorai.005G028600 & $2501120-2504324$ & $\|$ \\
\hline Gorai.005G028900 & $2553716-2557308$ & $\|$ \\
\hline Gorai.005G029000 & $2565325-2569455$ & $\|$ \\
\hline Gorai.005G029100 & $2585224-2589560$ & $\|$ \\
\hline Gorai.005G029200 & $2596425-2600231$ & $\|$ \\
\hline Gorai.005G029300 & $2613108-2617044$ & $\|$ \\
\hline Gorai.005G029400 & $2632315-2635858$ & $\|$ \\
\hline Gorai.005G031500 & $2804242-2806833$ & III \\
\hline Gorai.005G031600 & $2810110-2813150$ & III \\
\hline Gorai.005G031700 & $2819656-2825365$ & III \\
\hline Gorai.005G031800 & $2833071-2838460$ & III \\
\hline Gorai.005G031900 & $2852829-2859789$ & III \\
\hline Gorai.005G032000 & $2870255-2876978$ & III \\
\hline Gorai.005G032100 & $2880034-2881241$ & III \\
\hline Gorai.005G032200 & $2898234-2905491$ & III \\
\hline Gh D02G0233 & $2749065-2751671$ & 1 \\
\hline Gh D02G0234 & $2757983-2759275$ & I \\
\hline Gh D02G0235 & $2766873-2769728$ & 1 \\
\hline Gh D02G0236 & $2780046-2781380$ & I \\
\hline Gh D02G0237 & $2787974-2791318$ & I \\
\hline Gh D02G0238 & $2800055-2803296$ & 1 \\
\hline Gh D02G0257 & $2942631-2946086$ & $\|$ \\
\hline Gh D02G0258 & $2962327-2965794$ & $\|$ \\
\hline Gh D02G0259 & $2979373-2983290$ & $\|$ \\
\hline Gh D02G0277 & $3219359-3311044$ & III \\
\hline Gh D02G0280 & $3391502-3393436$ & III \\
\hline Gh D02G0281 & $3410121-3412647$ & III \\
\hline Gh D02G0282 & $3466152-3467675$ & III \\
\hline
\end{tabular}

Gene name with prefix 'Gorai' are from G. raimondii and those with prefix 'Gh' are from $G$. hirsutum

$24.5 \%$ PV explained, lower than the 45 to $47 \%$ PV explained in our earlier study when both QTLs were segregating in the population [9]. The suppression of egg production with $q M i-C 14$ alone appears to be lower in the absence of the $q M i-C 11$ locus, further supporting the hypothesis that the combination of both QTLs with different modes of action provides the genetic basis for transgressive segregation in the Auburn 623RNR germplasm $[8,9]$. Similar transgressive resistance to rootknot nematode resulting from epistatic interaction have been reported in cotton. For example, Wang et al. [37] reported that the gene RKN2 from the susceptible G. barbadense cultivar Pima S-7 can significantly enhance the level of resistance to $\mathrm{RKN}$ in the Acala NemX resistance source. In addition to cotton, interlocus interactions among main effect resistance QTLs have been observed in pepper [38] and soybean [39], suggesting that epistasis is common and constitutes a major component of host-plant resistance to pest and disease pathogens.

The reference genome sequence of the diploid G. raimondii [33] and draft sequence of the tetraploid Upland cotton G. hirsutum [40, 41] have provided the cotton community an unprecedented resource for genome analysis. In this study, we were able to narrow the confidence interval for $q \mathrm{Mi}-\mathrm{C} 14$ to a $3.9 \mathrm{cM}$ region and identify 20 candidate resistance genes with conserved LRR domains clustering in three groups (Fig. 4). This is not surprising as NBS-LRR genes are frequently clustered in plant genomes, and can contain genes conferring resistance to diverse pathogens, thereby acting as reservoirs of genetic variation for resistance specificities [17]. More importantly, of the six RKN resistance genes that have now been cloned in plants, all fall into a family of genes with the classic LRR motif typical of disease resistance genes (R-genes) [42]. Not all genes may be expressed at a given time but specific $\mathrm{R}$ genes may be triggered by the avirulence ( $A v r$ ) factor of the invading pathogen, and result in activation of a gene-for-gene resistance mechanism. Since a majority of disease resistance genes are comprised of arrays of hypervariable potential ligand-binding sites, interallelic recombination within these arrays along with unequal recombination may be the primary mechanism behind rapid evolution of $R$ genes and their clustering in the genome [43].

To further investigate the role of these LRR genes in disease resistance, we performed a Blast search of GenBank to identify annotated genes from species for which the genome sequence is available. Except for the gene Gorai.005G026700 and its tetraploid genome counterpart Gh D02G0238 that showed high similarity with a Theobroma cacao leucine-rich repeat protein kinase family protein isoform (accession No. XP_007034190.1), all other candidate genes from cluster I and II (Group I and II on the cladogram) showed high similarity with a Theobroma cacao Verticillium wilt disease resistancelike protein (up to $82 \%$ sequence similarity to accession XM_007034192.1). Genes in cluster III showed high homology with a Theobroma cacao receptor like protein (accession XM_007010859.1). This observation is not 

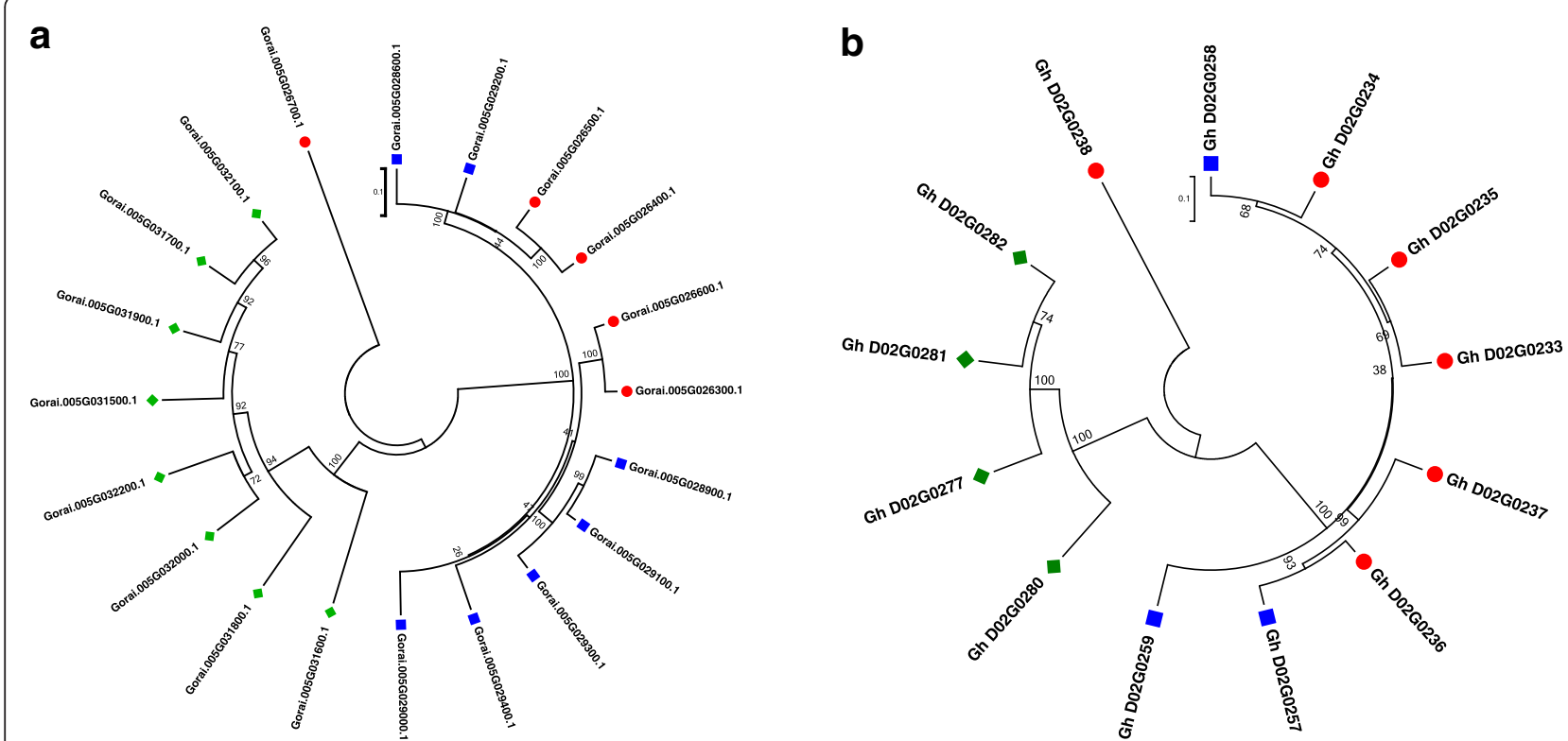

Fig. 4 Phylogenetic relationships among the candidate genes with LRR motifs near the qMi-C11 locus, from G. raimondii (panel a) and G. hirsutum (panel b). Red dots, blue squares and green diamond represent genes from Group I, II, and III, respectively

uncommon - as noted in earlier studies, $R$ genes in a disease resistance cluster encode protein motifs that are components of signal transduction systems including genes coding for protein receptors and protein kinases. For example, the $\mathrm{Xa21} R$ gene cluster in rice is composed of more than eight LRR and protein kinase genes while the $M$ locus in flax and RPP5 locus in Arabidopsis are comprised of genes with NBS-LRR and Tollinterleukin like protein receptor domains [44]. Molecular studies have shown that some $R$ genes in a disease resistance cluster share some degree of sequence similarity with other genes but are functionally divergent. For example, Prf, an NBS-LRR $R$ gene, is located within a cluster of five protein kinase homologs (Pto). Both Prf and Pto genes are required for resistance to Pseudomonas syringae pv. tomato [44], suggesting that resistance is conferred by a haplotype rather than an individual gene.

Among 20 positional candidate LRR genes, sequencing of the QTL interval of the resistant germplasm GA120R1B3 (derived from Auburn 623RNR) revealed only four to have non-synonymous mutations in the coding region (Table 2), suggesting these to be more probable candidates than the others. The observation that the SNP containing LRR gene Gorai.005G026500 belongs to cluster-I and Gorai.005G028600, Gorai. 005G029200, and Gorai.005G029400 belong to cluster-II implicates one of these two clusters in RKN resistance. Such non-synonymous mutations in the coding region are likely to have caused changes in the structure and function of the encoded protein, but the effects of these mutations are currently unknown.

Although no nematode resistance genes have been cloned via map-based cloning in cotton, a polypeptide called Meloidogyne Induced Cotton or MIC protein has been observed to be differentially expressed in root galls of resistant and susceptible cotton plants [45]. Further analyses on the $M I C$ protein led to the identification of the $M I C-3$ gene family with at least 15 MIC-like cDNAs that encode cotton-specific pathogenesis-related proteins [46, 47]. Overexpression of $M I C-3$ in a RKN susceptible cotton line showed 60-70 \% reduction in RKN egg production when compared to non-transgenic controls [40]. Further, overexpression of $M I C-3$ does not affect RKNinduced root galling. Therefore, the $M I C$ gene family produced a similar phenotypic effect as $q M i-C 14$, reducing nematode egg production but not root galling. However, our BLAST search against the $G$. hirsutum genome database using the MIC sequence (Accession No. AY072783) showed no MIC-like genes in or near the $q M i-C 14$ region, precluding $M I C$ family members as candidate genes for this QTL. Nonetheless, given that $M I C$ expression and effects are strongly correlated with RKN resistance, it is possible that this gene family represents a type of pathogenesis-related gene in which the effect is at the "end-point" in the signaling cascade that is regulated by gene(s) annotated in the $q M i-C 14$ locus. 
Table 2 Details of non-synonymous SNPs that differentiate genes from GA120R1B3 (RKN resistant) and Acala Maxxa (susceptible) lines in the QTL region flank by Gorai.005G026300 and Gorai.005G032200

\begin{tabular}{|c|c|c|c|c|c|c|c|c|c|c|c|}
\hline Gene ID & Position & Strand & Ref allele & $\begin{array}{l}\text { Susceptible } \\
\text { allele }\end{array}$ & $\begin{array}{l}\text { Resistant } \\
\text { allele }\end{array}$ & Ref aa & $\begin{array}{l}\text { Susceptible } \\
\text { aa }\end{array}$ & $\begin{array}{l}\text { Resistant } \\
\text { aa }\end{array}$ & $\begin{array}{l}\text { SNP } \\
\text { location }\end{array}$ & Pfam & Annotated function \\
\hline Gorai.005G026500 & 2345728 & + & $\mathrm{T}$ & $\mathrm{T}$ & G & $\mathrm{F}$ & $\mathrm{F}$ & L & CDS & PF08263,PF00560,PF13855 & receptor like protein 7 \\
\hline Gorai.005G027700 & 2415658 & - & $\mathrm{T}$ & $\mathrm{T}$ & G & . & & & 3-UTR & PF02826,PF05221 & S-adenosyl-L-homocysteine hydrolase \\
\hline Gorai.005G028100 & 2458792 & - & $\mathrm{T}$ & $\mathrm{T}$ & C & & . & . & 3-UTR & PF00076 & glycine-rich RNA-binding protein 2 \\
\hline Gorai.005G028100 & 2459025 & - & A & A & G & . & . & & 3-UTR & PF00076 & glycine-rich RNA-binding protein 2 \\
\hline Gorai.005G028100 & 2460937 & - & A & A & $\mathrm{T}$ & . & & & 5-UTR & PF00076 & glycine-rich RNA-binding protein 2 \\
\hline Gorai.005G028500 & 2499549 & + & C & C & $\mathrm{T}$ & & & . & 3-UTR & PF05653 & Protein of unknown function (DUF803) \\
\hline Gorai.005G028600 & 2502813 & + & $\mathrm{T}$ & T & A & $\mathrm{S}$ & $\mathrm{S}$ & $\mathrm{R}$ & CDS & PF08263,PF00560,PF13855 & receptor like protein 7 \\
\hline Gorai.005G028600 & 2502817 & + & G & G & A & $\mathrm{D}$ & $\mathrm{D}$ & N & CDS & PF08263,PF00560,PF13855 & receptor like protein 7 \\
\hline Gorai.005G029200 & 2599856 & + & G & G & $\mathrm{T}$ & K & K & N & CDS & PF08263,PF13855 & receptor like protein 6 \\
\hline Gorai.005G029200 & 2599857 & + & A & A & $\mathrm{T}$ & I & 1 & $\mathrm{~F}$ & CDS & PF08263,PF13855 & receptor like protein 6 \\
\hline Gorai.005G029400 & 2632994 & + & $\mathrm{T}$ & $\mathrm{T}$ & C & V & V & A & CDS & PF08263,PF13855 & receptor like protein 6 \\
\hline Gorai.005G029400 & 2634053 & + & G & G & C & $S$ & $S$ & $\mathrm{~T}$ & CDS & PF08263,PF13855 & receptor like protein 6 \\
\hline Gorai.005G029600 & 2657576 & + & G & G & A & A & A & A & CDS & PF00119 & ATPase, F0 complex, subunit A protein \\
\hline Gorai.005G029600 & 2657842 & + & G & G & A & $\mathrm{R}$ & $\mathrm{R}$ & Q & CDS & PF00119 & ATPase, F0 complex, subunit A protein \\
\hline Gorai.005G030200 & 2695818 & - & $\mathrm{T}$ & $\mathrm{T}$ & A & . & & & 3-UTR & PF01564,PF08241 & $\begin{array}{l}\text { S-adenosyl-L-methionine-dependent methyltransferases } \\
\text { superfamily protein }\end{array}$ \\
\hline Gorai.005G030800 & 2750823 & - & G & G & A & & . & . & $5-U T R$ & PF05856 & protein binding \\
\hline Gorai.005G031000 & 2760819 & + & C & C & $\mathrm{T}$ & & . & . & 5-UTR & PF02892,PF02902,PF05699 & BED zinc finger ; hAT family dimerisation domain \\
\hline Gorai.005G031000 & 2761040 & + & A & A & C & . & . & & $5-U T R$ & PF02892,PF02902,PF05699 & BED zinc finger ; hAT family dimerisation domain \\
\hline Gorai.005G031000 & 2761073 & + & A & A & G & & . & . & $5-U T R$ & PF02892,PF02902,PF05699 & BED zinc finger ;hAT family dimerisation domain \\
\hline Gorai.005G031000 & 2761385 & + & C & C & A & $\mathrm{R}$ & $\mathrm{R}$ & S & CDS & PF02892,PF02902,PF05699 & BED zinc finger ; hAT family dimerisation domain \\
\hline Gorai.005G031000 & 2761993 & + & G & G & C & K & K & N & CDS & PF02892,PF02902,PF05699 & BED zinc finger ; hAT family dimerisation domain \\
\hline Gorai.005G031000 & 2761995 & + & C & C & G & $\mathrm{T}$ & T & $\mathrm{S}$ & CDS & PF02892,PF02902,PF05699 & BED zinc finger ;hAT family dimerisation domain \\
\hline Gorai.005G031000 & 2762049 & + & A & A & G & $\mathrm{E}$ & $\mathrm{E}$ & G & CDS & PF02892,PF02902,PF05699 & BED zinc finger ; hAT family dimerisation domain \\
\hline Gorai.005G031000 & 2768718 & + & A & A & G & $\mathrm{N}$ & $\mathrm{N}$ & D & CDS & PF02892,PF02902,PF05699 & BED zinc finger ; hAT family dimerisation domain \\
\hline Gorai.005G031000 & 2768729 & + & A & A & $\mathrm{T}$ & $P$ & $P$ & P & CDS & PF02892,PF02902,PF05699 & BED zinc finger ; hAT family dimerisation domain \\
\hline
\end{tabular}


From a practical breeding perspective, until the causal gene for $q M i-C 14$ is identified, it might be prudent to simultaneously target all three clusters of $\mathrm{R}$ genes from the resistant parent to ensure horizontal and possibly stable RKN immunity of new cultivars. Tightly linked markers are therefore important for detecting recombination events that may result in segregation of these $R$ gene clusters, as well as to identify the zygosity of selected plants during marker-assisted selection. Our results further point to the dominant nature of this QTL as indicated by non-significant differences between the heterozygous and homozygous classes of resistance alleles. This scenario can potentially render selection based solely on phenotypic observation less effective in cotton breeding populations, and may have contributed to difficulties in fixing resistance alleles during the development of the highly resistant germplasm line GA 120R1B3 [48].

\section{Conclusion}

In this study, we validated an earlier observation that the qMi-C14 resistance locus mostly suppress egg production but has little effect on galling, further supporting the hypothesis that the effectiveness of RKN resistance from Auburn 623RBR is due to synergistic effects of two different mechanisms of RKN resistance. In addition, we have delimited qMi-C14 to a physical contig of about 2.3 $\mathrm{Mb}$ and identified 20 positional candidate LLR genes, including four of which containing non-synonomous mutation in the coding region. The candidate genes identified warrant functional studies that will help in identifying and characterizing the actual qMi-C14 defense gene(s) against root-knot nematodes.

\section{Additional files}

Additional file 1: Figure S1. Distribution of types of SSRs in the $4 \mathrm{Mb}$ telomeric region of chromosome 5 of $\mathrm{G}$. raimondii. (DOCX $30 \mathrm{~kb}$ )

Additional file 2: Table S1. Primer sequences of newly mapped SSRs developed from G. raimondii sequences. (DOCX $14 \mathrm{~kb}$ )

\section{Abbreviations}

LRR, leucine rich repeat, LOD, likelihood of odds ratio, NBS, nucleotide binding site, QTL, quantitative trait locus, RKN, root-knot nematodes, RNR, root-knot nematode resistant, SSR, simple sequence repeats

\section{Acknowledgments}

We thank Jennifer McCurdy for technical assistance; Ed Lubbers and Mychele Batista Da Silva for valuable comments.

\section{Funding}

We appreciate financial support from the Georgia Cotton Commission and Cotton Incorporated.

\section{Availability of data and materials}

The sequences of all candidate genes were obtained from the reference genome sequence of G. raimondii and G. hirsutum, which are publicly available in the CottonGen database (http://www.cottongen.org). The data utilized in the alignment and phylogenetic analysis can be found in Treebase (http://purl.org/phylo/treebase/phylows/study/TB2:S19559).

\section{Authors' contributions}

YH, PK, RS and XS developed the interspecific F2 population and performed the SSR genotyping work. RD performed the phenotypic evaluations. $H G$, AP and DP analyzed the genome sequences of Acala Maxxa and GA120R1B3. $B N, A P, D P$, and PC assisted in drafting of the manuscript. All authors read and approved the final manuscript.

\section{Competing interests}

The authors declare that they have no competing interests.

\section{Consent for publication}

Not applicable.

Ethics approval and consent to participate

Not applicable.

\section{Author details}

${ }^{1}$ Cotton Molecular Breeding Laboratory, University of Georgia, Tifton, GA 31793, USA. ${ }^{2}$ USDA-ARS, Crop Protection and Management Research Unit, Tifton, GA 31793, USA. ${ }^{3}$ Plant Genome Mapping Laboratory, University of Georgia, Athens, GA 30602, USA. Institute for Genomics, Biocomputing \& Biotechnology, Mississippi State University, Mississippi State, MS 39762, USA. ${ }^{5}$ Cotton Incorporated, 6399 Weston Parkway, Cary, NC 27513, USA. ${ }^{6}$ Present Address: Biotechnology Institute, Jiangsu Academy of Agricultural Sciences, Nanjing 210014, China. ${ }^{7}$ Present Address: College of Agronomy and Biotechnology, Southwest University, Chongqing 400716, China.

Received: 17 December 2015 Accepted: 19 July 2016

Published online: 08 August 2016

\section{References}

1. Sasser J, Freckman D. A world perspective on nematology: The role of the society. In: Veech JA, Dickson DW, editors. Vistas on Nematology. Hyattsville, MD: Society of Nematologists; 1987. p. 7-14.

2. Starr JL, Koenning SR, Kirkpatrick TL, Robinson AF, Roberts PA, Nichols RL. The future of nematode management in cotton. J Nematol. 2007;39(4): 283-94.

3. Robinson AF, Cook CG. Root-knot and reniform nematode reproduction on kenaf and sunn hemp compared with that on nematode resistant and susceptible cotton. Ind Crop Prod. 2001;13(3):249-64.

4. Shepherd RL. Transgressive segregation for root-knot nematode resistance in cotton. Crop Sci. 1974;14(6):872-5.

5. Shepherd RL. Registration of Auburn 623 RNR cotton germplasm (Reg. -No. GP 20). Crop Sci. 1974;14:911

6. Shen XL, He YJ, Lubbers EL, Davis RF, Nichols RL, Chee PW. Fine mapping QMi-C11 a major QTL controlling root-knot nematodes resistance in Upland cotton. Theor Appl Genet. 2010;121(8):1623-31.

7. Shen XL, Van Becelaere G, Kumar P, Davis RF, May OL, Chee P. QTL mapping for resistance to root-knot nematodes in the M-120 RNR Upland cotton line (Gossypium hirsutum L.) of the Auburn 623 RNR source. Theor Appl Genet. 2006;113(8):1539-49.

8. Gutierrez OA, Jenkins JN, McCarty JC, Wubben MJ, Hayes RW, Callahan FE. SSR markers closely associated with genes for resistance to root-knot nematode on chromosomes 11 and 14 of Upland cotton. Theor Appl Genet. 2010;121(7):1323-37.

9. He YJ, Kumar P, Shen XL, Davis RF, Van Becelaere G, May OL, Nichols RL, Chee PW. Re-evaluation of the inheritance for root-knot nematode resistance in the Upland cotton germplasm line M-120 RNR revealed two epistatic QTLs conferring resistance. Theor Appl Genet. 2014;127(6): 1343-51.

10. Creech RG, Jenkins JN, Tang B, Lawrence GW, Mccarty JC. Cotton Resistance to Root-Knot Nematode.1. Penetration and Reproduction. Crop Sci. 1995; 35(2):365-8.

11. Jenkins JN, Creech RG, Tang B, Lawrence GW, Mccarty JC. Cotton Resistance to Root-Knot Nematode.2. Post-Penetration Development. Crop Sci. 1995; 35(2):369-73.

12. Zhou E, Starr J, Smith C. Inheritance of resistance to Meloidogyne incognita in the cotton cultivar Acala NemX. J Nematol. 1999;31:584-5. 
13. McPherson GR, Jenkins JN, McCarty JC, Watson CE. Combining ability analysis of root-knot nematode resistance in cotton. Crop Sci. 1995;35(2): 373-5.

14. Zhang J, Waddell C, Sengupta-Gopalan C, Potenza C, Cantrell R. Diallel analysis of root-knot nematode resistance based on galling index in upland cotton. Plant Breed. 2007;126(2):164-8.

15. Gilbert JC, McGuire DC. Inheritance of resistance to severe root knot from Meloidogyne incognita in commercial type tomatoes. Proc Am Soc Hort Sci. 1956;68:437-42.

16. Milligan SB, Bodeau J, Yaghoobi J, Kaloshian I, Zabel P, Williamson VM. The root knot nematode resistance gene Mi from tomato is a member of the leucine zipper, nucleotide binding, leucine-rich repeat family of plant genes. Plant Cell. 1998;10(8):1307-19.

17. Gururani MA, Venkatesh J, Upadhyaya CP, Nookaraju A, Pandey SK, Park SW. Plant disease resistance genes: current status and future directions. Physiol Mol Plant Pathol. 2012;78:51-65.

18. Jones DA, Jones J. The role of leucine-rich repeat proteins in plant defences. Adv Bot Res. 1997;24:89-167.

19. Jaillais $Y$, Belkhadir $Y$, Balsemão-Pires $E$, Dangl $J \mathrm{~L}$, Chory J. Extracellular leucine-rich repeats as a platform for receptor/coreceptor complex formation. Proc Natl Acad Sci. 2011:108(20):8503-7.

20. Matsushima N, Miyashita H. Leucine-rich repeat (LRR) domains containing intervening motifs in plants. Biomolecules. 2012;2(2):288-311.

21. Hussey R, Barker K. Comparison of methods of collecting inocula of Meloidogyne spp., including a new technique, Plant disease reporter. 1973.

22. Bridge J, Page SLJ. Estimation of Root-Knot Nematode Infestation Levels on Roots Using a Rating Chart. Trop Pest Manage. 1980;26(3):296-8.

23. You FM, Huo N, Gu YQ, Luo M-c, Ma Y, Hane D, Lazo GR, Dvorak J, Anderson OD. BatchPrimer3: a high throughput web application for PCR and sequencing primer design. BMC Bioinformatics. 2008;9(1):253.

24. Chee PW, Rong J, Williams-Coplin D, Schulze SR, Paterson AH. EST derived PCR-based markers for functional gene homologues in cotton. Genome. 2004;47(3):449-62.

25. Zhang J, Guo W, Zhang T. Molecular linkage map of allotetraploid cotton (Gossypium hirsutum L. x Gossypium barbadense L.) with a haploid population. Theor Appl Genet. 2002;105:1166-74.

26. Lander ES, Botstein D. Mapping Mendelian factors underlying quantitative traits using RFLP linkage maps. Genetics. 1989:121(1):185.

27. Kosambi D. The estimation of map distances from recombination values. Ann Eugen. 1944;12(3):172-5.

28. Wang S, Basten C, Zeng Z. Windows QTL cartographer 2.5. Raleigh, NC: Department of Statistics, North Carolina State University; 2005.

29. Doerge $R$, Churchill G. Permutation tests for multiple loci affecting a quantitative character. Genetics. 1996;142(1):285

30. Edgar RC. MUSCLE: a multiple sequence alignment method with reduced time and space complexity. BMC Bioinformatics. 2004;5(1):113.

31. Tamura K, Stecher G, Peterson D, Filipski A, Kumar S. MEGA6: molecular evolutionary genetics analysis version 6.0. Mol Biol Evol. 2013;30(12):2725-9.

32. Guo H, Wang X, Gundlach H, Mayer KF, Peterson DG, Scheffler BE, Chee PW, Paterson AH. Extensive and biased intergenomic nonreciprocal DNA exchanges shaped a nascent polyploid genome, Gossypium (Cotton). Genetics. 2014;197(4):1153-63.

33. Paterson AH, Wendel JF, Gundlach $\mathrm{H}$, Guo H, Jenkins J, Jin D, Llewellyn D, Showmaker KC, Shu S, Udall J. Repeated polyploidization of Gossypium genomes and the evolution of spinnable cotton fibres. Nature. 2012 492(7429):423-7.

34. Li H, Durbin R. Fast and accurate short read alignment with BurrowsWheeler transform. Bioinformatics. 2009;25(14):1754-60.

35. Li H. A statistical framework for SNP calling, mutation discovery, association mapping and population genetical parameter estimation from sequencing data. Bioinformatics. 2011;27(21):2987-93.

36. Li H, Handsaker B, Wysoker A, Fennell T, Ruan J, Homer N, Marth G, Abecasis $G$, Durbin R. The sequence alignment/map format and SAMtools. Bioinformatics. 2009;25(16):2078-9.

37. Wang C, Ulloa M, Roberts PA. A transgressive segregation factor (RKN2) in Gossypium barbadense for nematode resistance clusters with gene rkn1 in G. hirsutum. Mol Gen Genomics. 2008;279(1):41-52

38. Lefebvre $\mathrm{V}$, Palloix A. Both epistatic and additive effects of QTLs are involved in polygenic induced resistance to disease: a case study, the interaction pepper-Phytophthora capsici Leonian. Theor Appl Genet. 1996:93(4):503-11.
39. Wu X, Blake S, Sleper DA, Shannon JG, Cregan P, Nguyen HT. QTL, additive and epistatic effects for SCN resistance in PI 437654. TAG Theor Appl Genet. 2009;118(6):1093-105.

40. Wubben M, Callahan F, Velten J, Burke J, Jenkins J. Overexpression of MIC-3 indicates a direct role for the MIC gene family in mediating Upland cotton (Gossypium hirsutum) resistance to root-knot nematode (Meloidogyne incognita). Theor Appl Genet. 2015;128(2):199-209.

41. Zhang T, Hu Y, Jiang W, Fang L, Guan X, Chen J, Zhang J, Saski CA, Scheffler BE, Stelly DM. Sequencing of allotetraploid cotton (Gossypium hirsutum L. acc. TM-1) provides a resource for fiber improvement. Nature biotechnology. 2015:33(5):531-7.

42. Caromel B, Gebhardt C. Breeding for Nematode Resistance: Use of Genomic Information. In: Genomics and Molecular Genetics of Plant-Nematode Interactions. Netherlands: Springer; 2011: p. 465-92.

43. Bergelson J, Kreitman M, Stahl EA, Tian D. Evolutionary dynamics of plant Rgenes. Science. 2001;292(5525):2281-5.

44. Michelmore RW, Meyers BC. Clusters of resistance genes in plants evolve by divergent selection and a birth-and-death process. Genome Res. 1998;8(11): 1113-30.

45. Zhang X-D, Callahan FE, Jenkins JN, Ma D-P, Karaca M, Saha S, Creech RG A novel root-specific gene, MIC-3, with increased expression in nematoderesistant cotton (Gossypium hirsutum L.) after root-knot nematode infection. Biochimica et Biophysica Acta (BBA)-Gene Structure and Expression. 2002; 1576(1):214-8.

46. Callahan F, Zhang X, Ma D, Jenkins J, Hayes R, Tucker M. Comparison of MIC-3 protein accumulation in response to root-knot nematode infection in cotton lines displaying a range of resistance levels. J Cot Sci. 2004;8:186-90.

47. Wubben MJ, Callahan FE, Hayes RW, Jenkins JN. Molecular characterization and temporal expression analyses indicate that the MIC (Meloidogyne Induced Cotton) gene family represents a novel group of root-specific defense-related genes in upland cotton (Gossypium hirsutum L.). Planta. 2008;228(1):111-23.

48. Davis RF, Chee PW, Lubbers EL, May OL. Registration of GA 120R1B3 Germplasm Line of Cotton. J Plant Regist. 2011;5(3):384-7.

\section{Submit your next manuscript to BioMed Central and we will help you at every step:}

- We accept pre-submission inquiries

- Our selector tool helps you to find the most relevant journal

- We provide round the clock customer support

- Convenient online submission

- Thorough peer review

- Inclusion in PubMed and all major indexing services

- Maximum visibility for your research

Submit your manuscript at www.biomedcentral.com/submit 